\title{
SvpA, a novel surface virulence-associated protein required for intracellular survival of Listeria monocytogenes
}

\author{
Elise Borezée, Elisabeth Pellegrini, Jean-Luc Beretti and Patrick Berche
}

Author for correspondence: Patrick Berche. Tel: +331406153 71. Fax: +33140615592.

e-mail: berche@necker.fr

Laboratoire de

Microbiologie, Institut

National de la Santé et de la Recherche Médicale U411, Faculté de Médecine Necker-Enfants Malades, 156 rue de Vaugirard, 75730 Paris Cedex 15, France
A previously unknown protein, designated SvpA (surface virulence-associated protein) and implicated in the virulence of the intracellular pathogen Listeria monocytogenes, was identified. This 64 kDa protein, encoded by svpA, is both secreted in culture supernatants and surface-exposed, as shown by immunogold labelling of whole bacteria with an anti-SvpA antibody. Analysis of the peptide sequence revealed that SvpA contains a leader peptide, a predicted C-terminal transmembrane region and a positively charged tail resembling that of the surface protein ActA, suggesting that SvpA might partially reassociate with the bacterial surface by its C-terminal membrane anchor. An allelic mutant was constructed by disrupting svpA in the wild-type strain LO28. The virulence of this mutant was strongly attenuated in the mouse, with a 2 log decrease in the $L D_{50}$ and restricted bacterial growth in organs as compared to the wild-type strain. This reduced virulence was not related either to a loss of adherence or to a lower expression of known virulence factors, which remained unaffected in the svpA mutant. It was caused by a restriction of intracellular growth of mutant bacteria. By following the intracellular behaviour of bacteria within bone-marrow-derived macrophages by confocal and electron microscopy studies, it was found that most svpA mutant bacteria remained confined within phagosomes, in contrast to wild-type bacteria which rapidly escaped to the cytoplasm. The regulation of svpA was independent of PrfA, the transcriptional activator of virulence genes in L. monocytogenes. In fact, SvpA was down-regulated by MecA, ClpC and ClpP, which are highly homologous to proteins of Bacillus subtilis forming a regulatory complex controlling the competence state of this saprophyte. The results indicate that: (i) SvpA is a novel factor involved in the virulence of $L$. monocytogenes, promoting bacterial escape from phagosomes of macrophages; (ii) SvpA is, at least partially, associated with the surface of bacteria; and (iii) SvpA is PrfA-independent and controlled by a MecAdependent regulatory network.

Keywords: microbial pathogenicity, surface protein, bacterial competence

\section{INTRODUCTION}

Listeria monocytogenes is a ubiquitous Gram-positive, facultative intracellular bacterium responsible for severe food-borne infections in humans and many animals (Gray \& Killinger, 1966). The virulence of this pathogen

The GenBank accession number for the sequence reported in this paper is AF282221. is due to its capacity to invade and multiply within host cells, including macrophages, hepatocytes, epithelial and endothelial cells. Early after internalization, bacteria disrupt the phagosomal membrane and access the cytoplasm where they polymerize actin and spread from cell to cell (Gaillard et al., 1987; Tilney \& Portnoy, 1989). Each step of the intracellular parasitism is dependent upon the production of virulence factors, including internalin (InlA), listeriolysin O (LLO), phospholipases and ActA, which are controlled by the 
pleiotropic transcriptional activator PrfA (Cossart \& Lecuit, 1998).

Like other intracellular pathogens, L. monocytogenes is exposed to hostile conditions during intracellular survival, including starvation, low $\mathrm{pH}$, chemical and enzymic stresses and elevated temperature. L. monocytogenes has evolved a complex adaptive network to maintain cell viability under stress and ensure persistence and growth both in the environment and occasionally in host tissues. In this network, stress proteins such as Clp (caseinolytic proteins) play a crucial role. Clp possess an ATPase activity and belong to the $100 \mathrm{kDa}$ heat-shock protein (HSP100) Clp family of highly conserved and universal molecular chaperones (Schirmer et al., 1996). They are involved in the folding and assembly of proteins, and in the regulation of ATPdependent proteolysis, ultimately promoting stressinduced resolubilization of aggregates (Gottesman \& Maurizi, 1992; Schirmer et al., 1996; Squires \& Squires, 1992). In Escherichia coli, ClpP alone degrades peptides less than 7 aa long (Woo et al., 1989). When associated with $\mathrm{ClpA}$ or $\mathrm{ClpX}$, ClpP expresses protease activity against specific substrates determined by the ATPase subunit (Gottesman et al., 1998; Larsen \& Finley, 1997; Wang et al., 1997). In L. monocytogenes, we previously found that two $\mathrm{Clp}, \mathrm{ClpC}$ and $\mathrm{ClpE}$, play an important role in stress tolerance and in vivo intracellular survival (Nair et al., 1999; Rouquette et al., 1996, 1998). We also identified a stress-induced serine protease ClpP, required for growth under stress conditions and playing a crucial role in intracellular survival of L. monocytogenes (Gaillot et al., 2000). ClpP modulates the production of LLO under stress conditions (Gaillot et al., 2000).

Clp also play regulatory functions in Bacillus subtilis, a genetically related soil Gram-positive bacterium. The $B$. subtilis ClpC protein, which is highly homologous to $\mathrm{ClpC}$ of L. monocytogenes, negatively controls bacterial competence, a physiological state allowing bacteria to efficiently internalize exogenous DNA. Indeed, ClpC of B. subtilis forms a ternary complex with MecA and ComK, leading to the sequestration and degradation of ComK, the key transcriptional activator of competence (Turgay et al., 1998). Recently, we identified a MecA homologue in L. monocytogenes. This protein mimics the regulatory function of $B$. subtilis MecA, repressing transcription of $\operatorname{comK}$, and subsequently $\operatorname{com} G$, when introduced in B. subtilis (Borezée et al., 2000a). Although we failed to demonstrate any competence in L. monocytogenes, many homologues of late competence gene products and competence regulatory proteins of $B$. subtilis are present in this pathogen (Borezée et al., 2000a). Interestingly, we found that a $64 \mathrm{kDa}$ secreted protein (p64) of L. monocytogenes accumulates in the supernatant of mecA, clpC and $c l p P$ mutants. These results suggested that $\mathrm{Mec}$ A of L. monocytogenes might belong to a signal transduction network involved in the regulatory processes of this pathogen (Borezée et al., 2000a).

In this work, we studied the role of this secreted protein by constructing an allelic mutant of the gene encoding this protein. We found that the $64 \mathrm{kDa}$ protein is required for intracellular survival and virulence of $L$. monocytogenes. This protein is a novel PrfA-independent factor implicated in the virulence of L. monocytogenes. It was designated SvpA for surface virulenceassociated protein, encoded by the gene supA.

\section{METHODS}

Bacterial strains, growth conditions and transformation. We used L. monocytogenes reference strain LO28 and E. coli $\mathrm{DH} 5$. All strains were routinely grown in Brain Heart Infusion (BHI) medium. Antibiotics were used at the following concentrations: ampicillin, $100 \mu \mathrm{g} \mathrm{ml}^{-1}$ for E. coli; erythromycin (Em), $8 \mu \mathrm{g} \mathrm{ml}^{-1}$ for L. monocytogenes and $200 \mu \mathrm{g} \mathrm{ml}^{-1}$ for E. coli; kanamycin $(\mathrm{Km}), 50 \mu \mathrm{g} \mathrm{ml}^{-1}$; colistin, $10 \mu \mathrm{g} \mathrm{ml}^{-1}$; nalidixic acid, $50 \mu \mathrm{g} \mathrm{ml}^{-1}$. Constructs were introduced into Listeria strains by conjugation or electroporation as described previously (Poyart et al., 1993). Bacterial growth and phenotype analysis of strains were performed as described by Rouquette et al. (1996). The metabolic profiles were determined on an API strip (50 substrates; BioMérieux).

DNA manipulations, RNA extraction and reverse transcription (RT) PCR. Chromosomal DNA, plasmid extraction, electrophoresis, restriction enzyme analysis, hybridizations and amplification by PCR were performed according to standard protocols (Sambrook et al., 1989). DNA sequencing was performed with the ABI-Prism 310 Sequencer (Perkin Elmer). Total RNA was extracted as described by Celli \& Trieu-Cuot (1998) from L. monocytogenes cultures grown until mid-exponential phase in BHI broth at $37^{\circ} \mathrm{C}$ and subjected to RT-PCR, as described previously (Borezée et al., $2000 \mathrm{~b})$. The following primers were used to amplify $s v p A$ and LiM00807.1 from chromosomal DNA or total RNA of LO28 and the svpA mutant strains: svpa (5'-CGGGATCCAAGGGGGATTATAATGAAGAAATTATGG-3') and svpb $5^{\prime}$ TCTAGATAACCCCGACCTAACTCGC-3'); 807a (5'-GGGGCCAAATTTGATCGTA-3') and 807b (5'-GTGCTTCTGGCGCATTC-3'), respectively.

Construction of an svpA-deleted mutant. An svpA mutant (LO28 svpA $\Omega a p h A 3$ ) was constructed by deletion of a $79 \mathrm{bp}$ internal fragment of svpA (nt 559-638) and insertion of a promoterless aphA-3 gene conferring resistance to $\mathrm{Km}$ (Menard et al., 1993) by double recombination. The deletion/replacement mutant of svpA was constructed by inserting a 964 bp EcoRI-BamHI LO28 DNA fragment ( - 397

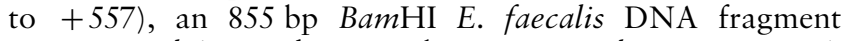
carrying aphA-3 and a 1119 bp BamHI-XbaI LO28 DNA fragment $(+634$ to +1746$)$, between the EcoRI and $X b a$ I sites of the thermosensitive shuttle vector pAUL-A (Chakraborty et

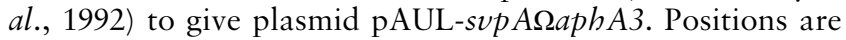
given relative to the translation initiation codon of $s v p A$. These three DNA fragments were generated by PCR using the following primers: mut1 (5'-GAATTCGGGCCTATGGGTTGAAGGGAACGC-3') and mut2 (5'-GGATCCGAAAGAGTCACAGGTGTTG-3'); km1 (5'-CGGGATCCCGACTAACTAGGAGGAATA-3') and km2 (5'-CGGGATCCCGGGTCATTATTCCCTCC-3'); mut3 (5'-GGATCCTGCTTG-

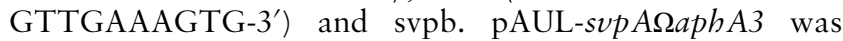
introduced into LO28 by electroporation and transformants were selected for Em resistance at $30^{\circ} \mathrm{C}$. We used a gene replacement procedure described by Chakraborty et al. (1992) to obtain an isogenic mutant carrying the disrupted svpA gene on the chromosome. The genotype of the mutant was confirmed by PCR sequencing and Southern blotting. 


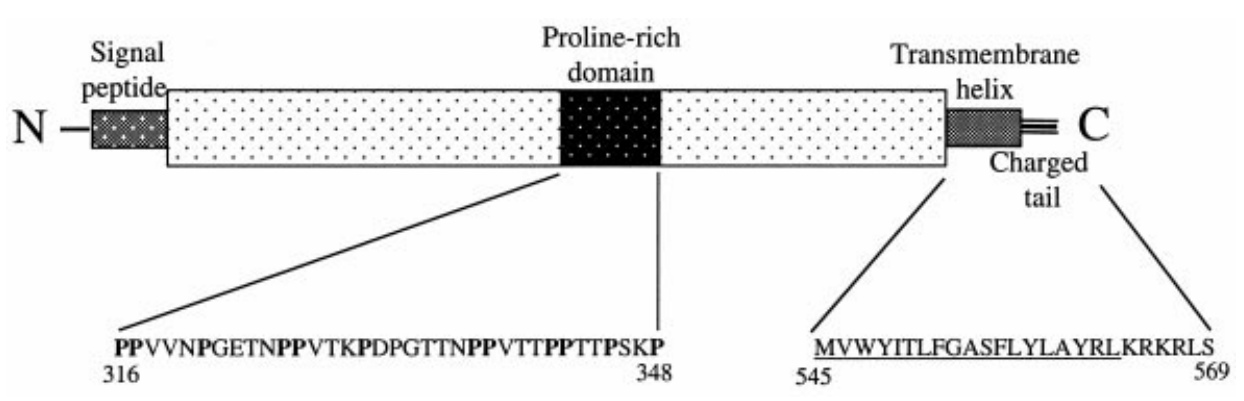

Fig. 1. Schematic representation of the SvpA protein of $L$. monocytogenes. The SvpA peptide sequence contains a signal peptide at the $\mathrm{N}$ terminus $(\mathrm{N})$, a large region with a central proline-rich domain and a $\mathrm{C}$-terminal region (C) composed of a transmembrane helix and a positively charged tail. The amino-acid sequence of the C-terminal region is indicated below and its hydrophobic domain is underlined. The amino acid sequence of the proline-rich domain is also indicated; proline residues are in bold.

Overproduction, purification of $\mathrm{His}_{6}-\mathrm{SvpA}$ and $\mathrm{His}_{6}-\mathrm{MecA}$ and antibody production. Plasmids pET-14b and pET$20 \mathrm{~b}(+)$ were used for protein overexpression and purification (Novagen). The L. monocytogenes supA and mecA genes were amplified by PCR using primers: svp1 (5'-CATATGAAGAAATTATGGAAAAAAGGCTTAGTAGC-3') and svp2 (5'GGATCCTTAACTCAATCTTTTACGTTTTAATCG-3'), mec1 (5'-CCATGGAAATTGAACGAATTAATGAGG-3') and mec2 (5'-GGATCCGAGAAGTGTTTTCTAATTTGCTTTAATG-3'), respectively. The svpA and mecA PCR products were then cloned into the $\mathrm{NdeI} / \mathrm{BamHI}$ sites of plasmid pET-14b and the NcoI/BamHI sites of pET20b(+), to generate $\mathrm{pET} v \mathrm{p} A$ and $\mathrm{pETmecA}$, respectively. These plasmids were used to transform E. coli strain BL21DE3 in which the T7 RNA polymerase gene is under the control of the inducible lacUV5 promoter. The recombinant strains were grown in LB medium at $37^{\circ} \mathrm{C}$ to mid-exponential exponential phase $\left(\mathrm{OD}_{600}=0 \cdot 7\right)$. IPTG $(1 \mathrm{mM})$ was then added and incubation continued for $2 \mathrm{~h}$. The cells were centrifuged, resuspended in 1/50 of the culture volume of PBS, disrupted by sonication and cell debris removed by centrifugation. E. coli crude extracts were loaded on a $1 \mathrm{ml}$ Poly-His Protein Purification Resin column (Roche) previously equilibrated with PBS and the $\mathrm{His}_{6}$-tagged proteins were eluted with an imidazole gradient $(10-500 \mathrm{mM})$. The eluted fractions were subjected to SDS-PAGE as described by Laemmli (1970). Protein concentrations were determined using the Bio-Rad protein assay (Bradford, 1976). Molecular size references markers were obtained from Life Technologies. The $\mathrm{His}_{6}{ }^{-}$ tagged proteins were used for custom antibody production in rabbits (Centre de Production Animale, Olivet, France).

Western blot analysis. Cultures of LO28 and mutant strains in the exponential growth phase were pelleted and supernatants collected and filtered. Supernatant protein extracts were prepared by TCA precipitation as described by Sambrook et al. (1989) and further concentrated with ultrafree columns (Millipore). The bacterial pellet was resuspended in $1 / 20$ of the culture volume of Tris $(10 \mathrm{mM}) /$ EDTA $(1 \mathrm{mM})$ and sonicated as described by Rouquette et al. (1998). Bacterial debris was removed by centrifugation and the resulting supernatant consisted of the cytoplasmic proteins. Supernatant and cytoplasmic protein extracts were analysed by Western blotting as described by Geoffroy et al. (1991). The membranes were incubated with rabbit polyclonal antibodies for $\mathrm{His}_{6}-\mathrm{SvpA}$ and $\mathrm{His}_{6}-\mathrm{MecA}$, or with mouse mAbs directed against purified LLO, ActA, InlA, InlB, PC-PLC (obtained from P. Cossart, Institut Pasteur, Paris, France). Anti-rabbit or anti-mouse immunoglobulin-peroxidase conjugates were used for immunodetection (Sigma). Enzymic activity was revealed by the addition of diamino-benzidine tetrahydrochloride (Sigma) supplemented with hydrogen peroxide $(0 \cdot 1 \%)$.

Infection of macrophages. Macrophages were infected at a bacterium/macrophage ratio of $1: 1$ and $15: 1$ for growth curves and microscopic studies, respectively. Bone-marrowderived macrophages from C57/BL6 mice were cultured and infected as previously described (Gaillot et al., 2000). After 15 min of bacterial adherence on ice, macrophages were exposed for $15 \mathrm{~min}$ at $37^{\circ} \mathrm{C}$ (time 0 ). The number of intracellular bacteria was estimated in cell lysates at selected intervals (from 0 to $8 \mathrm{~h}$ post-infection). Double fluorescence labelling of F-actin and bacteria was performed as described by Kocks et al. (1992) using phalloidin coupled to Oregon Green 488 (Molecular Probes) and a rabbit anti-Listeria serum (J. Rocourt, Institut Pasteur, Paris, France) revealed with an anti-IgG antibody coupled to Alexa 546 (Molecular Probes). Images were scanned on a Zeiss LSM 510 confocal microscope.

Culture of Caco-2 cells and adhesion assays. The human colon carcinoma Caco-2 cell line was propagated as described by Gaillard \& Finlay (1996). All incubations were carried out in a $10 \% \mathrm{CO}_{2}$ atmosphere at $37^{\circ} \mathrm{C}$. Cells were seeded at $10^{5}$ cells $\mathrm{cm}^{-2}$ onto $12 \mathrm{~mm}$ diameter glass coverslips in 24-well plates. Monolayers were used $24 \mathrm{~h}$ after seeding. Bacteria were grown for $16 \mathrm{~h}$ in BHI broth, pelleted, washed once and diluted appropriately in DMEM. Cells were inoculated with bacteria at a ratio of 100 bacteria per cell and incubated for $1 \mathrm{~h}$. They were subsequently washed, fixed and processed for immunolabelling as described by Milohanic et al. (2000). Coverslips were mounted on slides and examined by fluorescence microscopy. Each assay was carried out in triplicate and repeated twice. Adherent bacteria were counted by examining 50 cells in randomly selected microscope fields.

Processing for electron microscopy. Macrophages were infected at a bacterium/macrophage ratio of $15: 1$, fixed for $1 \mathrm{~h}$ at room temperature and processed as described previously (de Chastellier \& Berche, 1994). The percentage of intraphagosomal or intracytoplasmic bacteria was determined at selected intervals post-infection $(0,4,6 \mathrm{~h})$ for 50-100 different cell profiles (about 100 bacteria were examined per time point). For immunogold labelling, bacteria were grown overnight in BHI broth and processed as described previously 


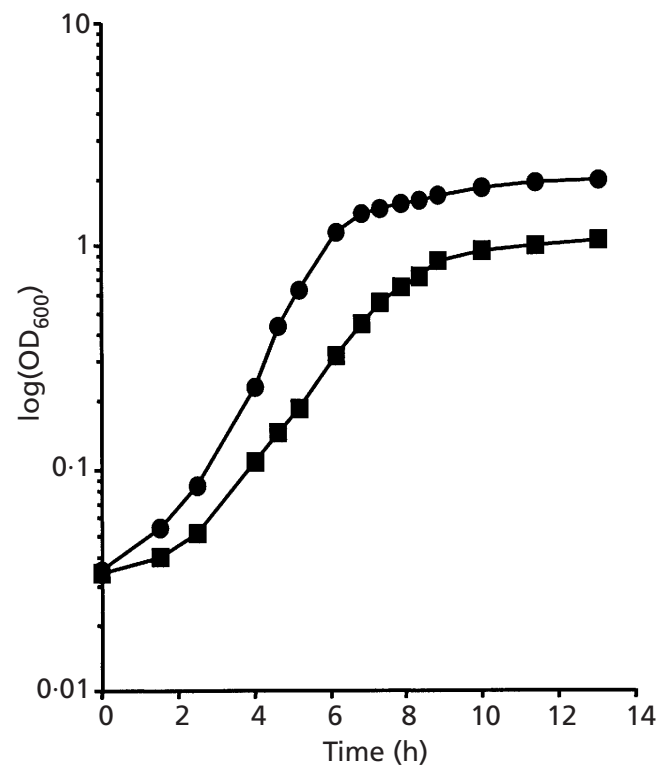

Fig. 2. Growth of L. monocytogenes LO28 wild-type (0) or svpA mutant ( $\square$ ) in $\mathrm{BHI}$ broth at $37^{\circ} \mathrm{C}$. Wild-type or svpA bacteria were grown at $37^{\circ} \mathrm{C}$ and $\mathrm{OD}_{600}$ was measured at various intervals.

(Gaillard et al., 1991). The grids were incubated for $1 \mathrm{~h}$ with rabbit anti-Listeria or rabbit anti-SvpA antibodies and further incubated with goat anti-rabbit $\operatorname{IgG}$ conjugated to $10 \mathrm{~nm}$ gold particles.

Mouse virulence assay. Six- to eight-week-old female Swiss mice (Janvier) were inoculated intravenously (i.v.) with various doses of bacteria (Gaillard et al., 1996). Mortality was followed over a $14-\mathrm{d}$ period on groups of five mice. The $\mathrm{LD}_{50}$ was determined by the probit method. Bacterial growth was followed in organs (spleen and liver) of mice infected i.v. with $8 \times 10^{5}$ bacteria as described by Nair et al. (1999).

\section{RESULTS}

\section{The svpA gene encodes a secreted protein}

We previously identified a secreted p64 protein of 569 aa $(63.4 \mathrm{kDa})$ of unknown function (Borezée et al., 2000a), encoded by a gene of 1707 nt designated svpA (GenBank accession no. AF282221). The genetic organization of the supA region of $\mathrm{LO} 28$ is similar to that of strain EGDE recently sequenced by the Listeria Genome Consortium. svpA corresponds to ORF LiM00806.1 of EGD$\mathrm{E}$ and is located upstream of ORF LiM00807.1, separated by a $114 \mathrm{bp}$ non-coding region. There is neither an obvious promoter nor any $\operatorname{prf} A$ boxes detectable in the upstream region of $s v p A$. A transcriptional analysis by Northern blotting failed to detect svpA transcripts in the parental strain LO28 and in the mec $A$ mutant, presumably due to unstable transcripts. However, we detected in LO28 specific svpA transcripts by RT-PCR using the primers svpa and svpb (data not shown).

As previously reported (Borezée et al., 2000a), the SvpA protein is identical to the product of ORF LiM00806.1 of strain EGD-E from the Listeria genome project. SvpA shares several repeated homologies with an ORF of 82 a encoded by the virulence plasmid pXO1 from Bacillus anthracis $(\sim 33 \%$ identity). Analysis of the peptide sequence of SvpA revealed three distinct regions: a peptide leader sequence with a predicted signal peptidase cleavage site between residues 28 and 29, a large region containing a proline-rich domain (residues 316 to 348), forming a predicted strong secondary structure and a stretch of 19 hydrophobic amino acids, presumed to

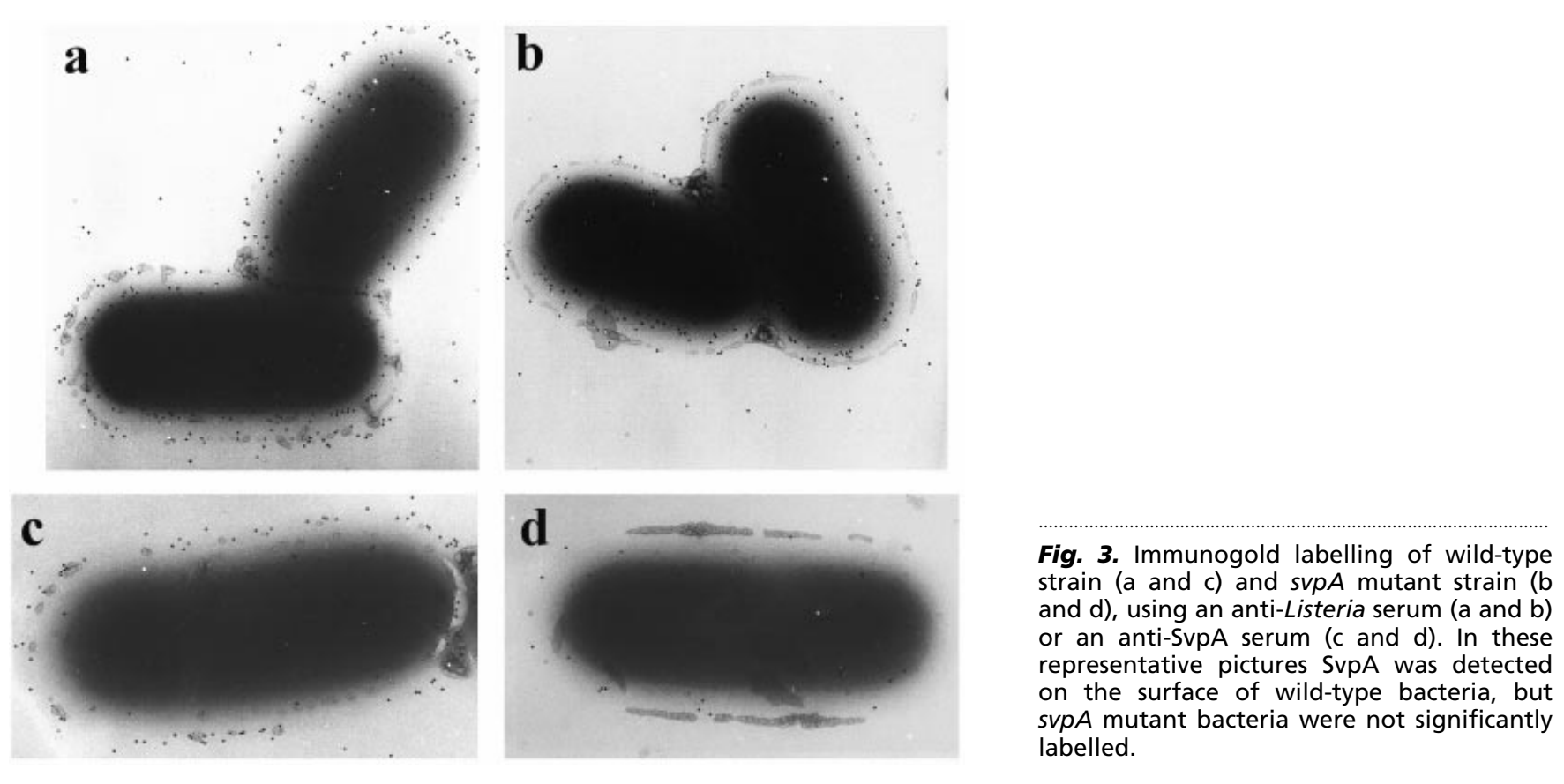




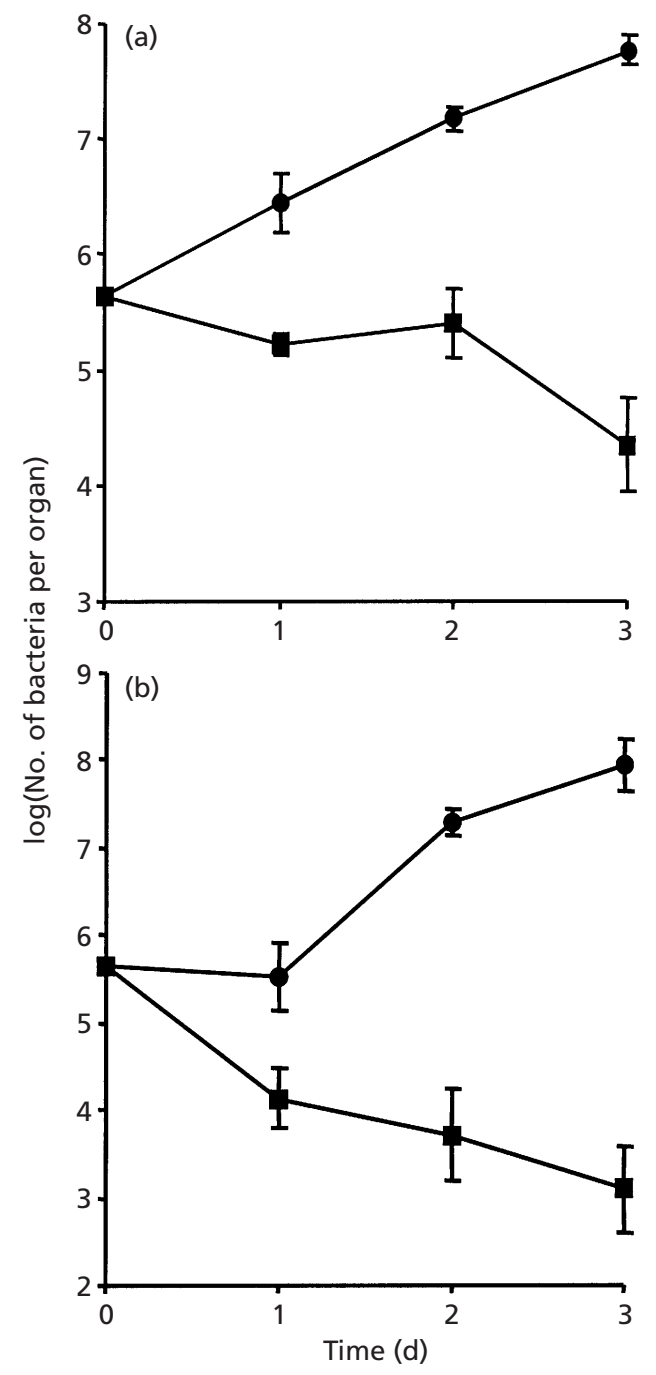

Fig. 4. Growth of L. monocytogenes LO28 wild-type (0) or svpA mutant ( $\boldsymbol{\square}$ ) in the spleen (a) or the liver (b) of mice inoculated i.v. with $10^{5 \cdot 6}$ bacteria.

form a transmembrane helix at the C-terminal extremity (residues 545-563) of the protein (Fig. 1). The hydrophobic region is followed by a tail of six residues, most of which are positively charged. The presence of a predicted peptide signal associated with a cleavage site is in accordance with the fact that SvpA is secreted in the culture supernatant. Nevertheless, it is possible that SvpA might reassociate to the bacterial surface by its predicted C-terminal transmembrane region.

\section{Construction and phenotypic analysis of a deleted svpA mutant}

An allelic mutant was constructed by deletion of an internal fragment of $s v p A$ and insertion of an $a p h A-3$ cassette by double-crossover into the chromosomal DNA of strain LO28, using a two-step procedure described by Chakraborty et al. (1992). The mutant was verified by Southern blotting and PCR sequencing of the svpA region. A transcriptional analysis was performed in wild-type and $s v p A$ mutant strains by RT-PCR using specific primers of $s v p A$ and of the downstream ORF LiM00807.1 mentioned above. In this mutant, the svpA transcript was larger in size due to the aphA-3 cassette insertion. The ORF LiM00807.1 transcript was present in both strains (data not shown), indicating that there is no polar effect due to the aphA-3 gene insertion in the mutant.

As compared with the parental strain LO28, the phenotypic analysis of the $s v p A$ mutant did not reveal any difference with respect to microscopic morphology (Gram staining), aspect of colonies, motility at $22^{\circ} \mathrm{C}$, the profiles of 50 metabolic characters using API-CH50, or the haemolytic activity on horse-blood agar plates (data not shown). Ultra-thin sections of bacteria were also examined by electron microscopy, which detected neither morphological difference nor any alteration in the bacterial cell wall (data not shown). Growth of the svpA mutant in BHI broth was moderately delayed at $37^{\circ} \mathrm{C}$, reaching a lower bacterial density at the stationary phase as compared to the wild-type strain (Fig. 2).

\section{SvpA is a surface-exposed protein}

Although SvpA is detected in culture supernatants, its predicted structure indicates a C-terminal sequence consisting of a 19 aa hydrophobic domain and a positively charged tail. This situation is reminiscent of that of other L. monocytogenes proteins, i.e. InlA (Gaillard et al., 1991) or ActA (Domann et al., 1992; Kocks et al., 1992; Lebrun et al., 1996), which are secreted and reassociated with the bacterial surface. We therefore tested the hypothesis that SvpA could be partially exposed on the bacterial surface. Wild-type and $\operatorname{svp} A$ mutant bacteria were immunolabelled using anti-SvpA serum. Whole bacteria were stained by the immunogold method and examined by electron microscopy. As a control, bacteria were also labelled with an anti-Listeria serum, revealing a strong labelling surrounding wild-type and svpA mutant bacteria (Fig. $3 a, b)$. With the anti-SvpA serum, wild-type bacteria were efficiently stained (about 102 gold particles per bacterium) (Fig. 3c), whereas a background labelling was seen with the supA mutant (about 25 gold particles per bacterium) as illustrated in Fig. 3(d). We conclude that the secreted SvpA might at least partially associate to the bacterial surface.

As the SvpA protein is present at the surface of $L$. monocytogenes, it might be implicated in the binding to non-professional phagocytic host cells. We tested the role of SvpA in the binding of L. monocytogenes to Caco- 2 cells, using a method described by Milohanic et al. (2000). We did not find any difference in the capacity to adhere to Caco-2 cells between the wild-type $(32 \pm 11$ bacteria per cell islet) and svpA mutant strains ( $36 \pm 12$ bacteria per cell islet), suggesting that SvpA itself does not play a role in adhesion. 
(a)

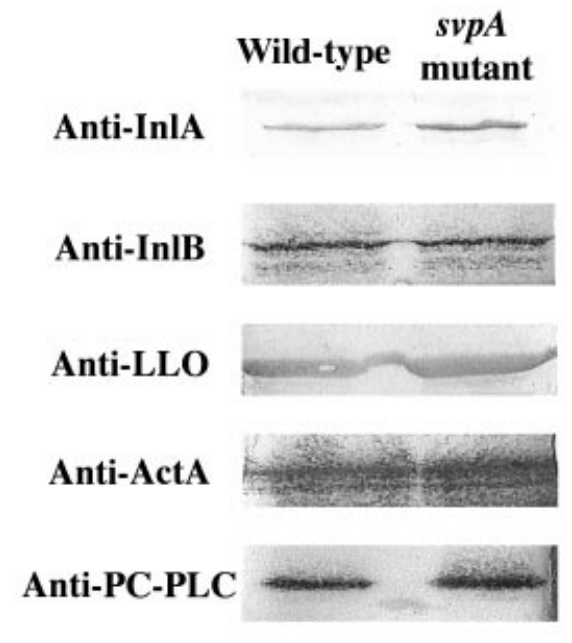

(b)

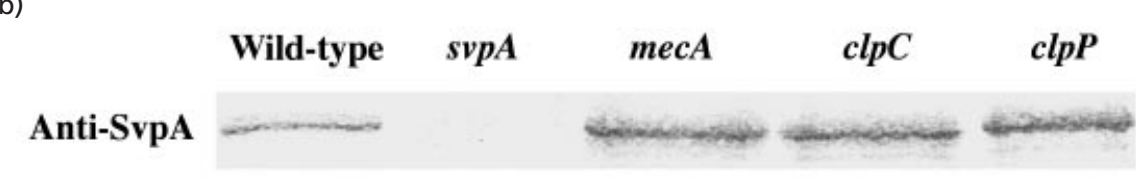

Anti-SvpA

(c)

\section{Anti-MecA}

Fig. 5. (a) Western blot analysis of culture supernatant extracts of wild-type and $\operatorname{svp} A$ mutant $L$. monocytogenes revealed with anti-InIA, anti-InIB, anti-LLO, anti-ActA and anti-PC-PLC antibodies. The expression of the known virulence factors LLO, ActA, PCPLC, InIA and InIB is not altered in the $\operatorname{svp} A$ mutant. (b) Western blot analysis of culture supernatant extracts of wild-type, svpA, $m e c A, \quad c l p C, \quad c l p P$ and prfA mutant $L$. monocytogenes using anti-SvpA antibodies. The expression of SvpA is controlled by MecA, ClpC and ClpP but does not depend on PrfA. (c) Western blot analysis of cytoplasmic extracts of wild-type, mecA, $\operatorname{svpA}, c / p C$ and clpP mutant L. monocytogenes revealed with anti-MecA antibodies. The MecA protein of $L$. monocytogenes accumulates in the $c / p C$ and $c l p P$ mutants.

\section{SvpA is required for the virulence of L. monocytogenes}

We studied the role of the secreted SvpA protein in the virulence of L. monocytogenes. The $\mathrm{LD}_{50}$ of LO28 and an svpA mutant were determined by inoculating (i.v.) Swiss mice with increasing doses of bacteria. The $\mathrm{LD}_{50}$ value of the svpA mutant was $10^{7 \cdot 2}$ bacteria per mouse, indicating a 2 log decrease compared to the wild-type strain $\left(10^{5}\right)$. Bacterial survival in organs was monitored over a period of $3 \mathrm{~d}$ by following the number of viable bacteria in the spleen and the liver of mice infected i.v. with $10^{5 \cdot 6}$ bacteria (Fig. 4). In contrast to the wild-type strain, which rapidly grew in organs until the death of mice, mutant bacteria were progressively eliminated in the liver and the spleen over the 3 -d period. The growth of the svpA mutant was severely restricted in the spleen and the liver, with a 3-4 log difference compared to the wild-type strain by day 3 post-infection (Fig. 4). We examined the expression of the main virulence factors in supernatants of wild-type and mutant bacteria (InlA, InlB, LLO, ActA, PC-PLC). They were not altered in the svpA mutant, as shown by Western blotting analysis with specific anti-sera (Fig. 5a). These results show the role of SvpA as a novel secreted factor required for virulence of L. monocytogenes.

\section{The expression of SvpA is controlled by MecA, ClpC and ClpP, and is PrfA-independent}

Using SDS-PAGE analysis, we previously found that SvpA (formerly termed p64) was overexpressed in the supernatants of the mecA, $c l p P$ and $c l p C$ mutants (Borezée et al., 2000a). This finding was confirmed by Western blotting analysis using a rabbit anti-SvpA serum raised against purified His-tagged SvpA. SvpA was not detected in the supernatant of the $\sup A$ mutant, as opposed to the wild-type strain, thus confirming that the expression of SvpA is abrogated in the mutant (Fig. 5b). SvpA is overexpressed in the mecA, $c l p P$ and $c l p C$ mutants (Fig. 5b). In contrast, the expression of SvpA is similar in LO28 and in a prfA mutant of LO28, showing that PrfA is not necessary to induce expression of svpA (Fig. 5b). We also purified $\mathrm{His}_{6}-\mathrm{MecA}$ with the His-tag system and prepared a rabbit anti-MecA serum. The expression of MecA was similar in cytoplasmic extracts of LO28 and of the svpA mutant (Fig. 5c), showing that SvpA does not regulate MecA. On the other hand, MecA 


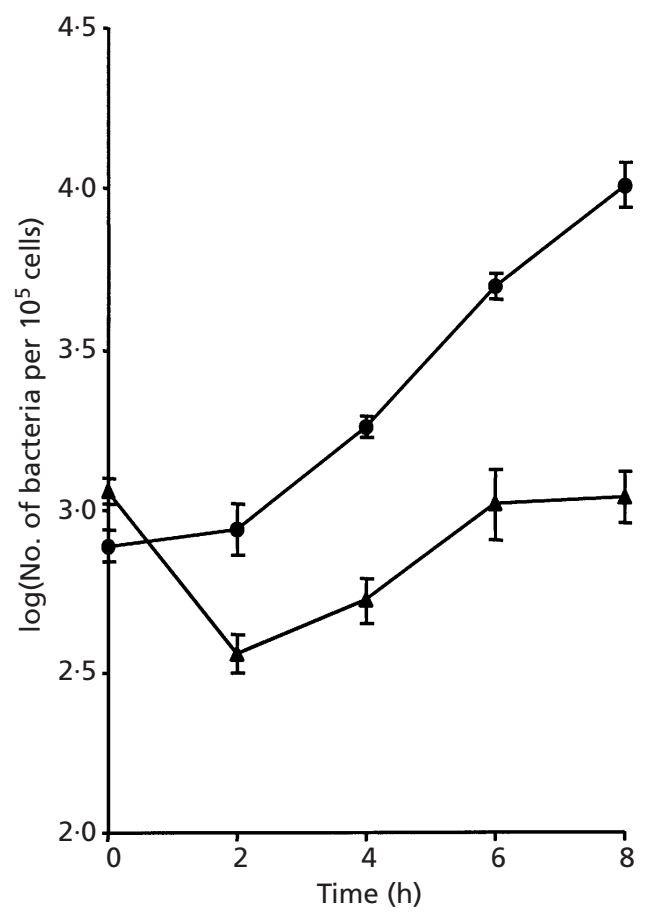

Fig. 6. Growth of L. monocytogenes LO28 wild-type (0) or svpA mutant ( $\boldsymbol{\Delta}$ ) in macrophages. Bone-marrow-derived macrophages from C57/BL6 mice were exposed for 15 min (time 0 ) to bacteria (1 bacterium per cell) and bacterial survival was followed for $8 \mathrm{~h}$ post-infection.

accumulated in the $c l p C$ and $c l p P$ mutants (Fig. 5c). This result is consistent with the apparent control of the $B$. subtilis MecA level by the ClpC/ClpP protease complex (Msadek et al., 1998; Turgay et al., 1998).

One might expect that the overexpression of SvpA could exacerbate the level of virulence of L. monocytogenes. So, we compared the level of virulence of LO28 with that of the mecA mutant. No significant difference was found, as determined by $\mathrm{LD}_{50}$ and the growth curves in the spleen and liver over a $3 \mathrm{~d}$ period as described above (data not shown). Conversely, we also tested the virulence of LO28 transformed with a multicopy plasmid harbouring mecA, which down-regulates the expression of SvpA. The virulence was attenuated in this strain as shown by the $\mathrm{LD}_{50}$ value estimated at $10^{7}$ per mouse as compared to $10^{5}$ for the wild-type strain. Altogether, these results indicate that: (i) SvpA is downregulated by $\mathrm{MecA}, \mathrm{ClpC}$ and $\mathrm{ClpP}$; (ii) SvpA is not controlled by the transcriptional activator PrfA controlling virulence genes; and (iii) the level of MecA is also controlled by ClpC and ClpP.

\section{SvpA is required for intracellular growth in macrophages}

The behaviour of the supA mutant and LO28 were studied in bone-marrow-derived macrophages from C57/BL6 mice. Macrophages were exposed to a bacterium/cell ratio of 1:1. As shown in Fig. 6, a similar amount of bacteria associated with macrophages was found at the onset of infection, suggesting that SvpA is not involved in the uptake by macrophages. After a latent phase of $2 \mathrm{~h}$, wild-type bacteria rapidly multiplied inside macrophages, inducing cellular lysis $6 \mathrm{~h}$ postinfection. In contrast, svpA mutant bacteria were partially killed in the first $2 \mathrm{~h}$ post-infection (decrease of $0.5 \mathrm{log}$ ), suggesting that the svpA mutant might be more susceptible to the bactericidal activity of phagosomes than wild-type bacteria. Surviving bacteria grew slowly until $6 \mathrm{~h}$ post-infection. Then, the number of viable bacteria remained stationary, without significant lysis of macrophages. These results indicate that SvpA plays an important role in the intracellular survival of L. monocytogenes.

\section{SvpA facilitates the bacterial escape from phagosomes of macrophages}

The intracellular fate of wild-type and $s v p A$ mutant bacteria was then studied by confocal microscopy in bone-marrow-derived macrophages (bacterium/cell $15: 1)$. Infected cells were examined at various intervals $(0,4$ and $8 \mathrm{~h})$ after double staining with an anti-Listeria antibody and with $\beta$-phalloidin to visualize F-actin. As found above, the early bacterial uptake (time 0) was similar for the wild-type and mutant bacteria (Fig. 7a and d). At 4 and $8 \mathrm{~h}$ post-infection, most wild-type bacteria were associated with polymerized actin, either surrounded by sheaths of actin, or, more often, forming comets tails (Fig. $7 \mathrm{~b}$ and c). In contrast, at $4 \mathrm{~h}$ postinfection, most mutant bacteria were apparently confined within phagosomes, with few bacteria associated with polymerized actin and comets (Fig. 7e). At $8 \mathrm{~h}$ post-infection, the total number of intracellular and intracytoplasmic mutant bacteria associated with actin or comets slowly increased, but remained much lower than those seen with wild-type bacteria (Fig. 7c and $\mathrm{f}$ ).

We performed a quantitative electron microscopic study on macrophages infected by LO28 or the svpA mutant under the conditions described above (see Methods). Intracytoplasmic wild-type bacteria reached 69 and $92 \%$ of the total number of intracellular bacteria 4 and $6 \mathrm{~h}$ post-infection, respectively. In contrast, only 22 and $41 \%$ of svpA mutant bacteria were visible inside the cytoplasm 4 and $6 \mathrm{~h}$ post-infection. Typical aspects of intracellular wild-type and mutant bacteria 4 and $6 \mathrm{~h}$ post-infection are illustrated in Fig. $8(\mathrm{a}-\mathrm{f})$. As expected, many wild-type bacteria escaped from the phagosomes at $4 \mathrm{~h}$ post-infection (Fig. 8a) and most bacteria were located inside the cytoplasm and surrounded with polymerized actin after $6 \mathrm{~h}$ (Fig. 8c, e). In contrast, a majority of $s v p A$ mutant bacteria remained confined in phagosomes where they were progressively destroyed (Fig. 8b, d, f). Rare bacteria surrounded by polymerized actin (Fig. 8b, d) and actin comets (Fig. 8d) were seen for the mutant 4 and $6 \mathrm{~h}$ post-infection, respectively. These results indicate that SvpA promotes the phagosomal escape of intracellular bacteria and the subsequent access to the cytoplasm of macrophages. 

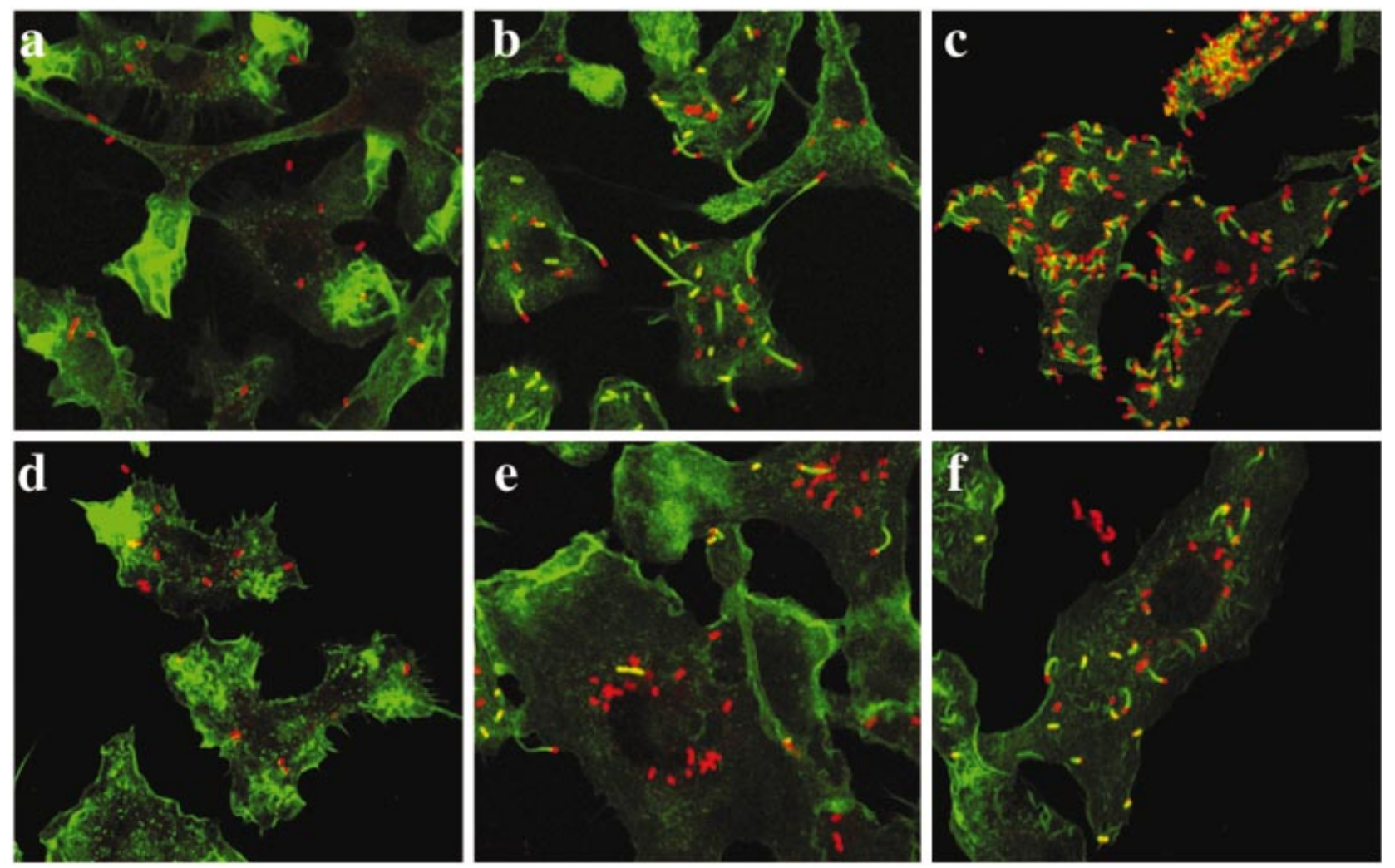

Fig. 7. Confocal microscopy of bone-marrow-derived mouse macrophages infected (15 bacteria per cell) with LO28 (a-c) or svpA mutant (d-f). Macrophages were observed at $0(a, d), 4(b, e)$ and $8 \mathrm{~h}(c, f)$ post-infection. F-actin was stained with phalloidin (green). Bacteria were labelled with an anti-Listeria serum (red). The majority of svpA mutant bacteria are not associated with actin and the intracellular growth is restricted.

\section{DISCUSSION}

In this study we identified a novel secreted protein, SvpA, involved in the virulence of L. monocytogenes. The role of this protein was studied by constructing an svpA-deleted mutant. The in vitro phenotypic analysis of this mutant revealed that it closely resembles the wildtype strain, except that its growth was impaired at $37^{\circ} \mathrm{C}$ (Fig. 2). The most important finding is that the virulence of a deleted supA mutant is strongly attenuated with a 2 $\log$ drop of the $\mathrm{LD}_{50}$ value $\left(10^{7 \cdot 2}\right.$ versus $\left.10^{5}\right)$. This loss of virulence was due to the restriction of bacterial growth in the spleen and liver of infected mice receiving a lethal challenge. We showed that SvpA plays an important role in the intracellular survival of L. monocytogenes. Mutant bacteria remained confined in phagosomes of bone-marrow macrophages, in contrast to wild-type bacteria, which rapidly escaped from phagosomes. This longer exposure to bactericidal activity of phagosomes in macrophage might explain that mutant bacteria were partially killed in the first $2 \mathrm{~h}$ post-infection, as compared to wild-type bacteria (Fig. 6). As a result, the intracellular growth was reduced in the mutant, with few bacteria escaping the phagosomes and multiplying in the cytoplasm of macrophages, without significant cellular lysis $6 \mathrm{~h}$ post-infection (Fig. 6). By confocal microscopy (Fig. 7) and quantitative electron micro- scopy, we confirmed that SvpA facilitates the bacterial escape from phagosomes since only $41 \%$ of mutants were seen in the cytoplasm 6 h post-infection, compared to $92 \%$ for wild-type bacteria. Many mutant bacteria remained confined in phagosomes (Fig. 8). These results indicate that SvpA promotes intracellular survival by facilitating the phagosomal escape of bacteria in macrophages.

Although the $64 \mathrm{kDa}$ SvpA is released in the culture supernatant (Fig. 5), this protein is also associated and exposed to the bacterial surface, as demonstrated by immunogold labelling (Fig. 3). However, SvpA is apparently not involved in bacterial adhesion to bonemarrow macrophages and Caco- 2 cells, since an supA mutant was efficiently internalized by macrophages and adhered normally to Caco-2 cells. The SvpA protein might be anchored to the bacterial membrane through its C-terminal hydrophobic region. Indeed, analysis of the peptide sequence revealed that SvpA possesses a peptide leader sequence, a large region containing a proline-rich domain and a predicted transmembrane segment followed by a short, positively charged tail at the $\mathrm{C}$ terminus (Fig. 1). This structure has similarity with some domains of ActA and InlA. Interestingly, these proteins are secreted and reassociated with the surface by their C-terminal domain. The hydrophobic 

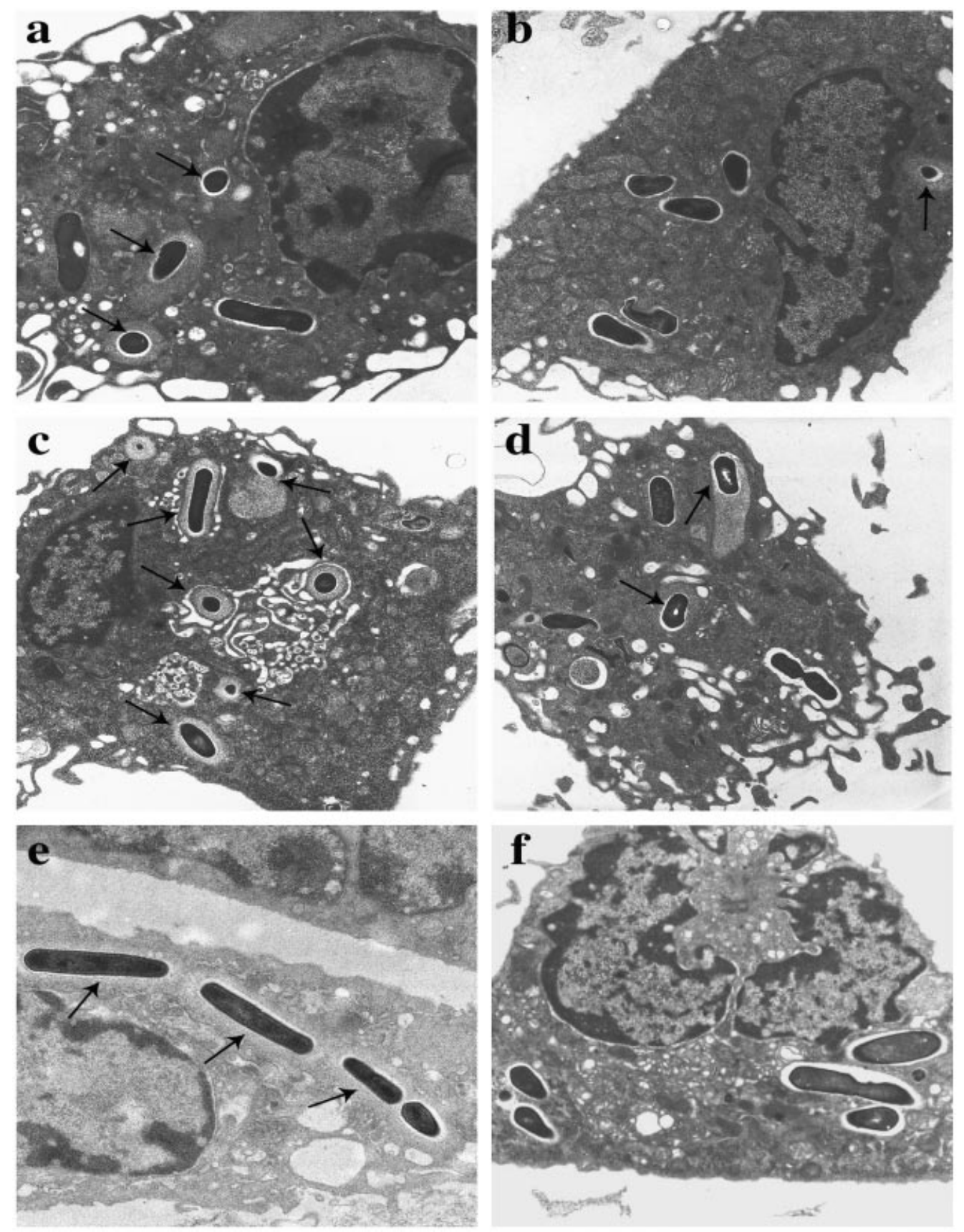

Fig. 8. Distribution of $L$. monocytogenes within macrophages. Bone-marrow-derived mouse macrophages were infected with the wild-type $(a, c, e)$ or $\operatorname{svp} A$ mutant $(b, d, f)$ strains and processed for electron microscopy at selected times postinfection (a-f). Ultra-thin sections of macrophages $4(a, b)$ and $6 \mathrm{~h}(\mathrm{c}-\mathrm{f})$ post-infection. Arrows indicate intracytoplasmic bacteria. About 70 and $90 \%$ of wild-type bacteria are free in the cytoplasm 4 (a) and $6 \mathrm{~h}$ (c, e) post-infection, respectively. Cytoplasmic bacteria are surrounded by actin sheets and many of them by a double membrane, a result typical of cell-to-cell spreading in adjacent cells. In contrast, the majority of svpA mutant bacteria are enclosed within phagosomes $(b, d, f)$. The small fraction of mutant bacteria accessing the cytoplasm could polymerize actin, as shown by an actin sheet $(b, d)$ and a typical actin comet (d).

region of InlA is preceded by the consensus motif LPXTG, required for the covalent anchoring of the protein to the cell wall (Lebrun et al., 1996). Nevertheless, surface proteins from Gram-positive bacteria exist which are not covalently anchored to the cell wall.
This is the case for ActA, a virulence factor involved in actin assembly and intracellular movement, which possesses a hydrophobic domain of 22 residues followed by 4 charged residues, without the LPXTG motif (Kocks et al., 1992). This surface protein is assumed to be 
anchored to the cytoplasmic membrane via its Cterminal transmembrane helix (Chakraborty, 1999). Similarly, SvpA could be tethered to bacteria without an LPXTG motif. Another interesting feature is that SvpA also possesses a proline-rich region of 32 aa. ActA also contains a central domain with four proline-rich repeats involved in the direct binding to cytoskeletal components of infected cells (Chakraborty, 1999; Niebuhr et al., 1997). It is known that these proline-rich motifs are often involved in protein-protein interactions (Kay et al., 2000). Although the significance of the proline-rich domain of SvpA is unknown, it is predicted to form a secondary structure that might interact with host-cell components during the intracellular parasitism of $L$. monocytogenes. Since SvpA presumably acts inside phagosomes, one could speculate that SvpA might interact with the components of the phagosomal membrane to promote bacterial escape from this cellular compartment. However, the function of SvpA remains unknown.

By studying the regulation of SvpA, we found that it is not controlled by the transcriptional activator controlling virulence genes, PrfA : a prfA mutant produced the same amount of SvpA in culture supernatants as that of wild-type bacteria (Fig. 5b). On the other hand, SvpA was down-regulated by MecA, ClpC and ClpP. Using an antiserum raised against purified SvpA, we found by Western blotting analysis that SvpA accumulates in the culture supernatants of $m e c A, c l p C$ and $c l p P$ mutants, as compared to the wild-type bacteria (Fig. 5b). SvpA might be part of a MecA-dependent regulatory network proposed previously (Borezée et al., 2000a). We previously found by heterologous complementation in $B$. subtilis that MecA of L. monocytogenes mimics the regulatory function of the $B$. subtilis MecA protein, presumably forming a complex with $\mathrm{ClpC}$ and $\mathrm{ClpP}$ to sequester and degrade ComK, a transcriptional activator of the late competence genes in B. subtilis (Turgay et al., 1997, 1998). The regulation of SvpA by MecA might be indirect and the expression of SvpA could be regulated by an unknown factor repressed by the MecA/ $\mathrm{ClpC} / \mathrm{ClpP}$ complex. We also found in the present study that L. monocytogenes MecA accumulates in the cytoplasm of the $c l p C$ and $c l p P$ mutants (Fig. 5c), suggesting that MecA might also be controlled by the ClpC/ClpP protease complex in this pathogen. In B. subtilis, MecA acts as a linker protein targeting ComK for proteolysis and is regulated by the same proteolytic complex (Msadek et al., 1998; Turgay et al., 1998). Although no competence could be detected in L. monocytogenes (Borezée et al., 2000a; Rouquette et al., 1998), homologues for many competence factors of B. subtilis exist in L. monocytogenes. The MecA-dependent network of this pathogen might play an important role in bacterial physiology, including the down-regulation of SvpA, a factor implicated in virulence.

In conclusion, our results suggest that SvpA is a novel PrfA-independent factor required for intracellular survival and belongs to a regulatory network involving $\mathrm{MecA}, \mathrm{ClpC}$ and ClpP. SvpA facilitates bacterial escape from phagosomes. SvpA might protect intraphagosomal bacteria from bacterial killing, and/or act synergistically with other virulence factors (listeriolysin O, phospholipases) or even directly to promote bacterial escape from phagosomes.

\section{ACKNOWLEDGEMENTS}

We kindly thank S. Nair for critical reading of the manuscript and Y. Goureau for technical assistance with confocal microscopy. E.B. received a fellowship from the Ministère de l'Education Nationale de la Recherche et de la Technologie. This work was supported by INSERM, The University of Paris V, and two grants from the European Commission (contracts ERBCHRXCT 94-0451 and CT980036).

\section{REFERENCES}

Borezée, E., Msadek, T., Durant, L. \& Berche, P. (2000a). Identification in Listeria monocytogenes of MecA, a homologue of the Bacillus subtilis competence regulatory protein. J Bacteriol 182, 5931-5934.

Borezée, E., Pellegrini, E. \& Berche, P. (2000b). OppA of Listeria monocytogenes, an oligopeptide-binding protein required for bacterial growth at low temperature and involved in intracellular survival. Infect Immun 68, 7069-7077.

Bradford, M. M. (1976). A rapid and sensitive method for the quantitation of microgram quantities of protein utilizing the principle of protein-dye binding. Anal Biochem 72, 248-254.

Celli, J. \& Trieu-Cuot, P. (1998). Circularization of Tn916 is required for expression of the transposon-encoded transfer functions: characterization of long tetracycline-inducible transcripts reading through the attachment site. Mol Microbiol 28, 103-117.

Chakraborty, T. (1999). Molecular and cell biological aspects of infection by Listeria monocytogenes. Immunobiology 201, 155-163.

Chakraborty, T., Leimeister-Wachter, M., Domann, E., Hartl, M., Goebel, W., Nichterlein, T. \& Notermans, S. (1992). Coordinate regulation of virulence genes in Listeria monocytogenes requires the product of the prfA gene. J Bacteriol 174, 568-574.

de Chastellier, C. \& Berche, P. (1994). Fate of Listeria monocytogenes in murine macrophages: evidence for simultaneous killing and survival of intracellular bacteria. Infect Immun 62, 543-553.

Cossart, P. \& Lecuit, M. (1998). Interactions of Listeria monocytogenes with mammalian cells during entry and actin-based movement: bacterial factors, cellular ligands and signaling. EMBO J 17, 3797-3806.

Domann, E., Wehland, J., Rohde, M. \& 7 other authors (1992). A novel bacterial virulence gene in Listeria monocytogenes required for host cell microfilament interaction with homology to the proline-rich region of vinculin. EMBO J 11, 1981-1990.

Gaillard, J. L. \& Finlay, B. B. (1996). Effect of cell polarization and differentiation on entry of Listeria monocytogenes into the enterocyte-like Caco-2 cell line. Infect Immun 64, 1299-1308.

Gaillard, J. L., Berche, P., Mounier, J., Richard, S. \& Sansonetti, P. (1987). In vitro model of penetration and intracellular growth of Listeria monocytogenes in the human enterocyte-like cell line Caco-2. Infect Immun 55, 2822-2829.

Gaillard, J. L., Berche, P., Frehel, C., Gouin, E. \& Cossart, P. (1991). Entry of L. monocytogenes into cells is mediated by internalin, a 
repeat protein reminiscent of surface antigens from gram-positive cocci. Cell 65, 1127-1141.

Gaillard, J. L., Jaubert, F. \& Berche, P. (1996). The inlAB locus mediates the entry of Listeria monocytogenes into hepatocytes in vivo. J Exp Med 183, 359-369.

Gaillot, O., Pellegrini, E., Bregenholt, S., Nair, S. \& Berche, P. (2000). The ClpP serine protease is essential for the intracellular parasitism and virulence of Listeria monocytogenes. Mol Microbiol 35, 1286-1294.

Geoffroy, C., Raveneau, J., Beretti, J. L., Lecroisey, A., VazquezBoland, J. A., Alouf, J. E. \& Berche, P. (1991). Purification and characterization of an extracellular 29-kilodalton phospholipase C from Listeria monocytogenes. Infect Immun 59, 2382-2388.

Gottesman, S. \& Maurizi, M. R. (1992). Regulation by proteolysis: energy-dependent proteases and their targets. Microbiol Rev 56, 592-621.

Gottesman, S., Roche, E., Zhou, Y. \& Sauer, R. T. (1998). The ClpXP and ClpAP proteases degrade proteins with carboxyterminal peptide tails added by the SsrA-tagging system. Genes Dev 12, 1338-1347.

Gray, M. L. \& Killinger, A. H. (1966). Listeria monocytogenes and listeric infections. Bacteriol Rev 30, 309-382.

Kay, B. K., Williamson, M. P. \& Sudol, M. (2000). The importance of being proline: the interaction of proline-rich motifs in signaling proteins with their cognate domains. FASEB J 14, 231-241.

Kocks, C., Gouin, E., Tabouret, M., Berche, P., Ohayon, H. \& Cossart, P. (1992). L. monocytogenes-induced actin assembly requires the act $A$ gene product, a surface protein. Cell 68, 521-531.

Laemmli, U. K. (1970). Cleavage of structural proteins during the assembly of the head of bacteriophage T4. Nature 227, 680-685.

Larsen, C. N. \& Finley, D. (1997). Protein translocation channels in the proteasome and other proteases. Cell 91, 431-434.

Lebrun, M., Mengaud, J., Ohayon, H., Nato, F. \& Cossart, P. (1996). Internalin must be on the bacterial surface to mediate entry of Listeria monocytogenes into epithelial cells. Mol Microbiol 21, 579-592.

Menard, R., Sansonetti, P. J. \& Parsot, C. (1993). Nonpolar mutagenesis of the ipa genes defines IpaB, IpaC, and IpaD as effectors of Shigella flexneri entry into epithelial cells. J Bacteriol 175, 5899-5906.

Milohanic, E., Pron, B., Berche, P. \& Gaillard, J. L. (2000). Identification of new loci involved in adhesion of Listeria monocytogenes to eukaryotic cells. European Listeria Genome Consortium. Microbiology 146, 731-739.

Msadek, T., Dartois, V., Kunst, F., Herbaud, M. L., Denizot, F. \& Rapoport, G. (1998). ClpP of Bacillus subtilis is required for competence development, motility, degradative enzyme synthesis, growth at high temperature and sporulation. Mol Microbiol 27, 899-914.
Nair, S., Frehel, C., Nguyen, L., Escuyer, V. \& Berche, P. (1999). ClpE, a novel member of the HSP100 family, is involved in cell division and virulence of Listeria monocytogenes. Mol Microbiol 31, 185-196.

Niebuhr, K., Ebel, F., Frank, R. \& 7 other authors (1997). A novel proline-rich motif present in ActA of Listeria monocytogenes and cytoskeletal proteins is the ligand for the EVH1 domain, a protein module present in the Ena/VASP family. EMBO J 16, 5433-5444.

Poyart, C., Abachin, E., Razafimanantsoa, I. \& Berche, P. (1993). The zinc metalloprotease of Listeria monocytogenes is required for maturation of phosphatidylcholine phospholipase C: direct evidence obtained by gene complementation. Infect Immun 61, 1576-1580.

Rouquette, C., Ripio, M. T., Pellegrini, E., Bolla, J. M., Tascon, R. I., Vazquez-Boland, J. A. \& Berche, P. (1996). Identification of a ClpC ATPase required for stress tolerance and in vivo survival of Listeria monocytogenes. Mol Microbiol 21, 977-987.

Rouquette, C., de Chastellier, C., Nair, S. \& Berche, P. (1998). The ClpC ATPase of Listeria monocytogenes is a general stress protein required for virulence and promoting early bacterial escape from the phagosome of macrophages. Mol Microbiol 27, 1235-1245.

Sambrook, J., Fritsch, E. F. \& Maniatis, T. (1989). Molecular Cloning: a Laboratory Manual, 2nd edn. Cold Spring Harbor, NY: Cold Spring Harbor Laboratory.

Schirmer, E. C., Glover, J. R., Singer, M. A. \& Lindquist, S. (1996). HSP100/Clp proteins: a common mechanism explains diverse functions. Trends Biochem Sci 21, 289-296.

Squires, C. \& Squires, C. L. (1992). The Clp proteins: proteolysis regulators or molecular chaperones? J Bacteriol 174, 1081-1085.

Tilney, L. G. \& Portnoy, D. A. (1989). Actin filaments and the growth, movement, and spread of the intracellular bacterial parasite, Listeria monocytogenes. J Cell Biol 109, 1597-1608.

Turgay, K., Hamoen, L. W., Venema, G. \& Dubnau, D. (1997). Biochemical characterization of a molecular switch involving the heat shock protein ClpC, which controls the activity of ComK, the competence transcription factor of Bacillus subtilis. Genes Dev 11, 119-128.

Turgay, K., Hahn, J., Burghoorn, J. \& Dubnau, D. (1998). Competence in Bacillus subtilis is controlled by regulated proteolysis of a transcription factor. EMBO J 17, 6730-6738.

Wang, J., Hartling, J. A. \& Flanagan, J. M. (1997). The structure of $\mathrm{ClpP}$ at $2 \cdot 3 \AA$ resolution suggests a model for ATP-dependent proteolysis. Cell 91, 447-456.

Woo, K. M., Chung, W. J., Ha, D. B., Goldberg, A. L. \& Chung, C. H. (1989). Protease Ti from Escherichia coli requires ATP hydrolysis for protein breakdown but not for hydrolysis of small peptides. J Biol Chem 264, 2088-2091.

Received 20 April 2001; revised 5 July 2001; accepted 10 July 2001. 